\title{
EQUILÍBRIO TERMODINÂMICO DO SISTEMA BUTANOL - LIQUIDO IÔNICO (PRÓTICO) - ÁGUA PARA APLICAÇÕES EM MEMBRANAS ELETROLÍTICAS DE CÉLULAS A COMBUSTÍVEL
}

\author{
J. P. S. SANTOS, R. MILAZZO, I. C. SALES, S. P. PINHO e S. MATTEDI \\ Universidade Federal da Bahia, Programa de Pós-Graduação em Engenharia Química \\ E-mail para contato: joaopaulosantos01@ @otmail.com
}

\begin{abstract}
RESUMO - Embora o uso de células a combustíveis já serem uma realidade, questões envolvendo armazenamento, transporte, segurança e custos, ainda representam desafios a serem superados para uma expansão mais acelerada dessa tecnologia. Nesse sentido, membranas eletrolíticas ancoradas com líquidos iônicos (MEALI) estão sendo estudadas, visando o aumento da eficiência e resistência térmica desses materiais, além da redução dos custos de produção e viabilização do uso de outras fontes combustíveis em substituição do hidrogênio. Portanto, o objetivo desse trabalho foi o estudo do equilíbrio líquido-líquido de uma mistura ternária (água-líquido iônico (LI)-butanol), cujo LI utilizado foi o acetato de n-metil-2-hidroxietilamônio, nas temperaturas 20,30 e $40{ }^{\circ} \mathrm{C}$. Assim foram identificadas as regiões de imiscibilidade do sistema e obtidos os valores de parâmetros de equilíbrio, que são de suma importância na avaliação da integridade da membrana eletrolítica na presença dessas espécies.
\end{abstract}

\section{INTRODUÇÃO}

Tem-se observado que nessas últimas décadas houve um aumento acentuado na produção e consumo energético por todo mundo. No entanto, majoritariamente, a energia utilizada é proveniente de fontes não renováveis, correspondendo a $92 \%$ de toda energia consumida mundialmente em dados de 2011 (Schutz et al, 2013). No Brasil esse quadro se mostra mais favorável ambientalmente, segundo a Empresa de Pesquisa Energética (2013), que produz os dados oficiais do Balanço Energético Nacional anualmente. Nesse relatório, observa-se que a produção de energia por fontes renováveis chegam a 42,4\%, principalmente, devido aos derivados de cana de açúcar e hidrelétricas. E ainda, que os setores de maior consumo são os de transporte $(31,3 \%)$ e industriais $(35,1 \%)$. Já no setor e transporte, mais de $80 \%$ da energia consumida são derivados de petróleo.

Diante esse cenário, visualiza-se a necessidade de utilização de novas tecnologias que proporcionem uma geração de energia de forma limpa e renovável, contribuindo para um desenvolvimento sustentável e amistoso ao ambiente. Nesse caminho, uma tecnologia que tem 


\section{9 a 22 de outubro de 2014 \\ Florianópolis/SC}

sido alvo de pesquisa intensiva e a cada ano tem crescido o número de aplicações e de participação no mercado, é a geração de energia elétrica a partir de células a combustível, dispositivos que transformam energia química a energia elétrica sem danos ao ambiente (Villullas et al, 2002).

Uma célula eletroquímica define-se como um dispositivo que utiliza reações de óxidoredução para produzir a interconversão de energia química e elétrica. Essa célula possui constituição básica dois eletrodos e um circuito externo, para a condução dos elétrons, e um eletrólito como condutor iônico (Russel, 1994). No processo de oxirredução, os reagentes podem ser adicionados ao sistema a partir de um reservatório externo, permitindo operação de forma contínua, esse sistema se caracteriza como uma célula a combustível. Um exemplo de uma célula a combustível que utiliza membrana como eletrólito, hidrogênio e oxigênio como reagentes do ânodo e do cátodo respectivamente é mostrada na Figura 1.

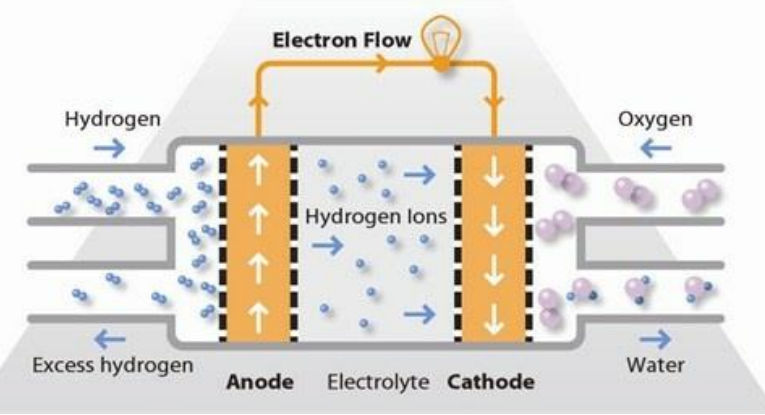

Figura 1 - Representação de uma célula a combustível de membrana. Extraído de: Fuel Cell Today (2012).

Apesar de apresentarem diversas vantagens ambientais e elevada eficiência quando comparadas a motores de combustão interna, as células a combustíveis de membrana, que são as mais promissoras à aplicação em veículos, possuem ainda alguns desafios a serem superados, como por exemplo, em relação ao combustível utilizado. O hidrogênio apresentou elevado potencial, principalmente, por ser abundante e possuir alta eficiência no processo. No entanto, seu armazenamento de forma segura e que represente custos economicamente viáveis, ainda não é uma realidade, principalmente quanto a autonomia em percursos longos, nos quais a tecnologia tradicional já atende (500 km, em média) ("Abastecendo com hidrogênio", 2014). Mas, apesar dos vários desafios ainda não superados no processo de implementação da tecnologia de células a combustíveis em automóveis, já se encontram no mercado modelos de veículos com essa tecnologia, em especial da empresa Honda (Calmon, 2014).

Como solução em termos de custos de instalação de postos de abastecimento, transporte e autonomia dos veículos, seria a utilização de combustíveis líquidos, como álcoois orgânicos, que já possuem infraestrutura desenvolvida no mercado, em células a combustíveis. No entanto, células de membranas com outros combustíveis alheios ao hidrogênio, apresentaram eficiência 
reduzida e desempenho e durabilidade inferior quando comparadas a células com utilização do hidrogênio (Fuel Cell Today, 2012).

Assim, são vários os esforços em pesquisas, a fim de se aprimorar as células a combustíveis com membrana a serem utilizadas de forma eficiente, segura e que apresente custos atrativos ao mercado vigente. Uma dessas linhas de pesquisa, estuda a utilização de sais líquidos a temperatura inferior a $100{ }^{\circ} \mathrm{C}$, conhecidos como líquidos iônicos (LI), como eletrólitos, incorporados na membrana polimérica. Esses LI, têm como principal função, o aumento da condutividade iônica do sistema e permitir a elevação da temperatura do meio reacional, que consequentemente, também contribui para o aumento de eficiência. Dessa forma, o objetivo desse trabalho foi o estudo da interação de um álcool combustível, como o butanol, em equilíbrio com o líquido iônico, que torna possível analisar o potencial de arraste, dos componentes que formam a célula, em relação ao LI incorporado na membrana. $\mathrm{O}$ estudo ainda se encontra em andamento e busca-se desenvolvê-lo para uma série de LI próticos, dentre eles, o acetato de n-metil-2hidroxietilamônio (m-HEAA), que foi utilizado nesse trabalho.

\section{METODOLOGIA}

O estudo se dividiu em três etapas: a síntese do m-HEAA, a construção da curva binodal e a contrução das linhas de amarração (tie lines).

\subsection{Síntese do m-HEAA}

$\mathrm{O}$ acetato de n-metil-2-hidroxietilamônio, foi sintetizado a partir da reação simples entre o ácido acético (com grau de pureza 99,8\%) e a base 2-metil-amino-etanol (com grau de pureza $>98 \%$ ), como se apresenta na Figura 2.<smiles>CC(=O)O</smiles>

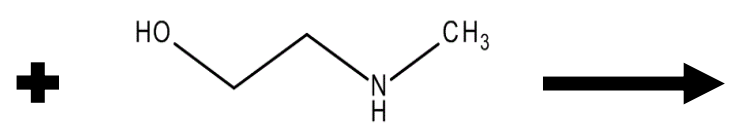<smiles>CC(=O)[O-]</smiles><smiles>C[NH2+]CCO</smiles>

Figura 2 - representação da equação química da reação de síntese do m-HEAA.

As massas de ambos reagentes, foram pesadas em balança analítica (Shimadzu, modelo AX200), em proporção estequiométrica. A mistura foi realizada em um sistema fechado, com atmosfera inerte, com o objetivo de minimizar a absorção de umidade do ar pelo LI formado, visto que o mesmo é hidrofílico. Na Figura 3, observa-se uma ilustração real do sistema utilizado, em que, a base foi previamente inserida no balão de 3 vias e o ácido (à esquerda), foi gotejado lentamente no balão. Nitrogênio foi introduzido periodicamente ao balão, para remoção do ar atmosférico e se manter uma atmosfera de reação inerte. Todo sistema foi resfriado com banho de gelo e um banho termostático de $10^{\circ} \mathrm{C}$, para se minimizar reações paralelas e evitar a perda de ácido acético por evaporação. 


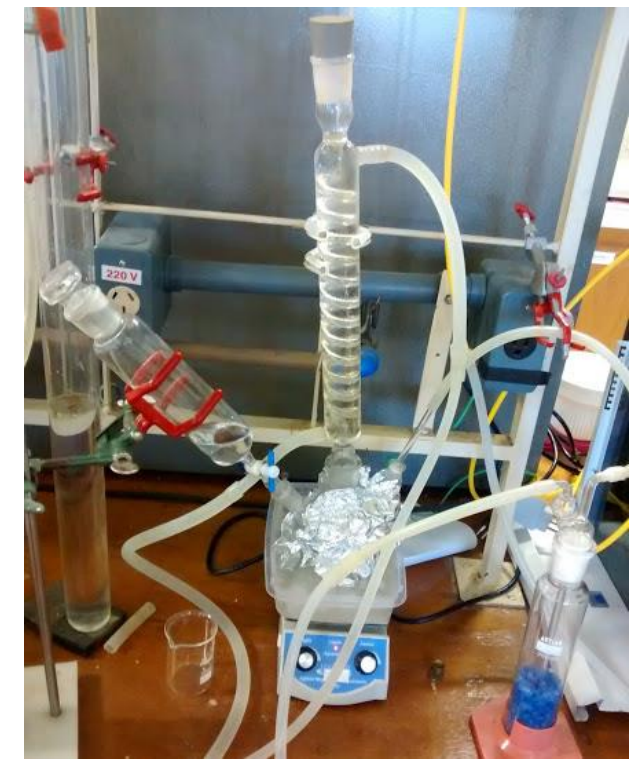

Figura 3 - Esquema da síntese, em atmosfera inerte, do m-HEAA.

Após a reação, o sistema foi submetido a um aquecimento de $40{ }^{\circ} \mathrm{C}$ sob vácuo, para remoção de reagentes remanescentes e umidade, por um período de 72 horas. Tanto o sistema reacional quanto o de secagem, foi protegido da luz para evitar possíveis reações indesejáveis. $\mathrm{O}$ produto formado foi analisado por meio de Karl Fisher (marca Schott, modelo TitroLine KF trace), em que foi quantificando a presença de água em 10,37\%. Adicionalmente, o LI formado foi verificado por meio de Ressonância Magnética Nuclear de H e C, quanto a presença de impurezas remanescentes da reação.

\subsection{Construção da curva binodal}

Para a construção da curva binodal foi utilizada uma célula com camisa, acoplada em uma banho termostático para controle da temperatura. Na célula, preenchida com água, foi introduzido um vail com uma quantidade previamente pesada (em balança analítica) de água, para construção da região rica em água, e butanol, para construção da região rica em butanol. O vail era fechado com tampa e septo, para evitar a evaporação do sistema. Assim, para construção da região rica em água, se adicionava o butanol, que promovia o turvamento da mistura, e posteriormente, se adicionava o m-HEAA para o desturvamento. Para a construção da região rica em butanol o processo foi análogo, com o turvamento a partir da adição de água e desturvamento, pela adição do m-HEAA. Todas as massas adicionadas foram pesadas em balança analítica e os valores foram registrados para construção da curva.

\subsection{Construção das linhas de amarração}

As linhas de amarração (tie lines) foram construídas utilizando-se tubos de ensaios com tampas. Como a região de imiscibilidade já definida, então foram adicionadas massas conhecidas dos três componentes em pontos distintos de mistura. Os tubos de ensaios foram agitados 
vigorosamente por 5 minutos e postos em descanso por 24 horas, para o estabelecimento da condição de equilíbrio. Para obtenção das composições de ambas as fases, utilizou-se a metodologia empregada no trabalho de Passos et al. (2012), em que se pesa a massa de topo ou de fundo do sistema em equilíbrio e se correlaciona essa massa com a distância entre ponto de mistura e a curva binodal. Para tanto, é necessário que os pontos experimentais da binodal se ajustem bem a uma curva, sendo assim utilizou-se o modelo proposto por Asenjo et al. (2002), que adota 3 parâmetros para representação da região de equilíbrio, segundo a Equação 1.

$$
y=A \cdot \exp \left(B \cdot x^{0,5}-C \cdot x\right)
$$

Em que $x$ e $y$ representam a fração mássica do componente em maior quantidade em cada fase, e A, B e C são os parâmetros dessa equação que foram estimados utilizando o software SigmaPlot, com o objetivo de se obter o menor desvio quadrático.

\section{RESULTADOS}

Como primeiro resultado os pontos obtidos para a mistura do sistema na temperatura de 20 ${ }^{\circ} \mathrm{C}$, bem como a curva ajustada e as linhas de amarração correspondentes, podem ser observados na Figura 4.
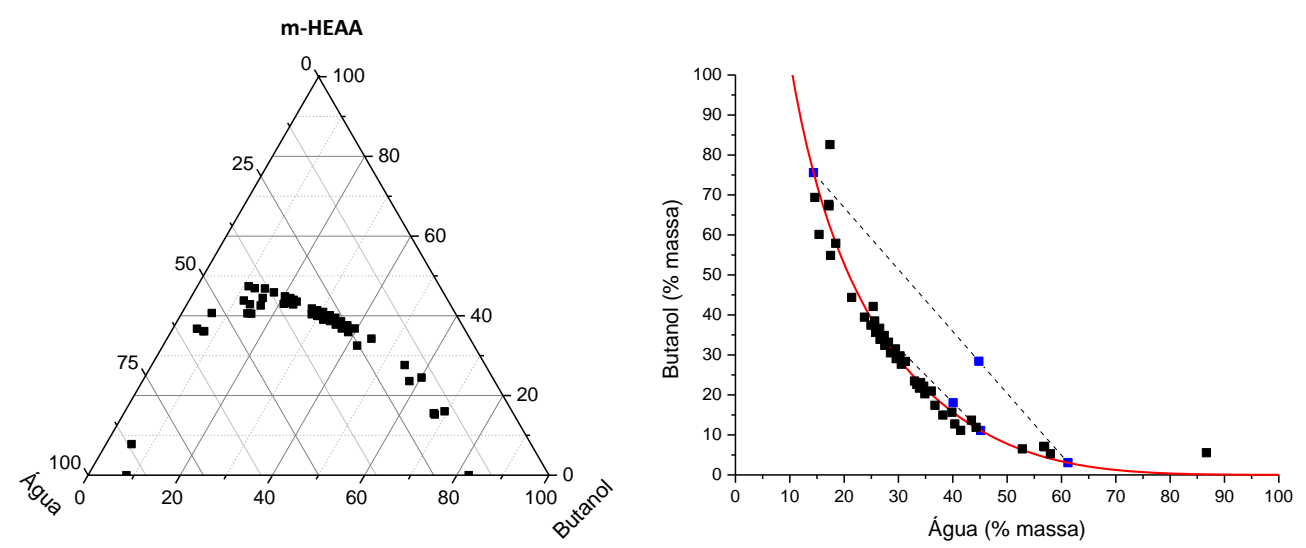

Figura 4 - Dados de equilíbrio do sistema água-butanol-m-HEAA, a $20{ }^{\circ} \mathrm{C}$.

Os parâmetros obtidos no ajuste da curva Butanol (y) vs Água (x) são mostrados na Tabela 1.

Tabela 1 - Parâmetros de regressão com a Equação 1, à temperatura de $20^{\circ} \mathrm{C}$.

\begin{tabular}{cccc}
\hline Parâmetros & Coeficiente & Desvio Padrão & P \\
\hline A & 217,669 & 18,452 & $<0,0001$ \\
B & $-0,278$ & 0,022 & $<0,0001$ \\
C & $9,258 \mathrm{E}-06$ & $1,079 \mathrm{E}-06$ & $<0,0001$ \\
\hline
\end{tabular}


À temperatura de $30^{\circ} \mathrm{C}$ foram obtidos os pontos e curvas representados na Figura 5.
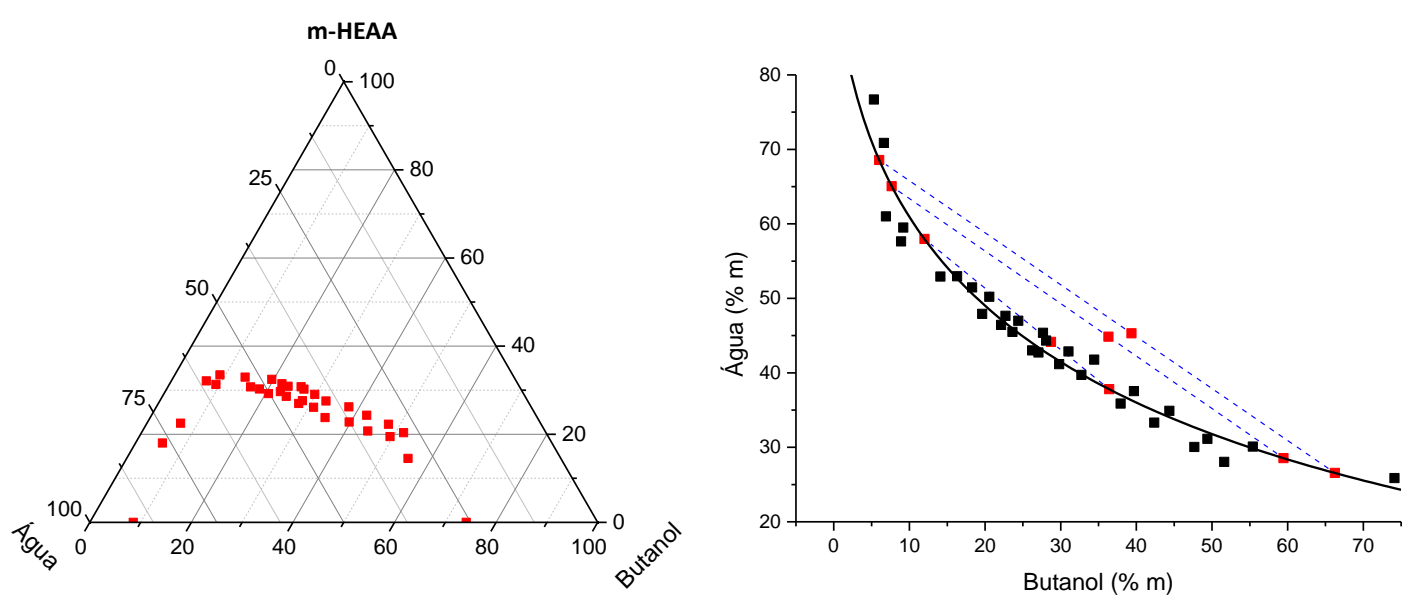

Figura 5 - Dados de equilíbrio do sistema água-butanol-m-HEAA, a $30{ }^{\circ} \mathrm{C}$. Tabela 2.

Os parâmetros que foram obtidos na curva de ajuste à temperatura $\left(30^{\circ} \mathrm{C}\right)$ são mostrados na

Tabela 2 - Parâmetros de regressão com a Equação 1, à temperatura de $30^{\circ} \mathrm{C}$.

\begin{tabular}{cccc}
\hline Parâmetros & Coeficiente & Desvio Padrão & P \\
\hline $\mathrm{a}$ & 102,982 & 4,095 & $<0,0001$ \\
$\mathrm{~b}$ & $-0,166$ & 0,01 & $<0,0001$ \\
$\mathrm{c}$ & $1,52 \mathrm{E}-08$ & $2,91 \mathrm{E}-07$ & 0,9587 \\
\hline
\end{tabular}

Por fim, para a temperatura de $40^{\circ} \mathrm{C}$ foram obtidos os seguintes pontos e curva mostrados na Figura 6.
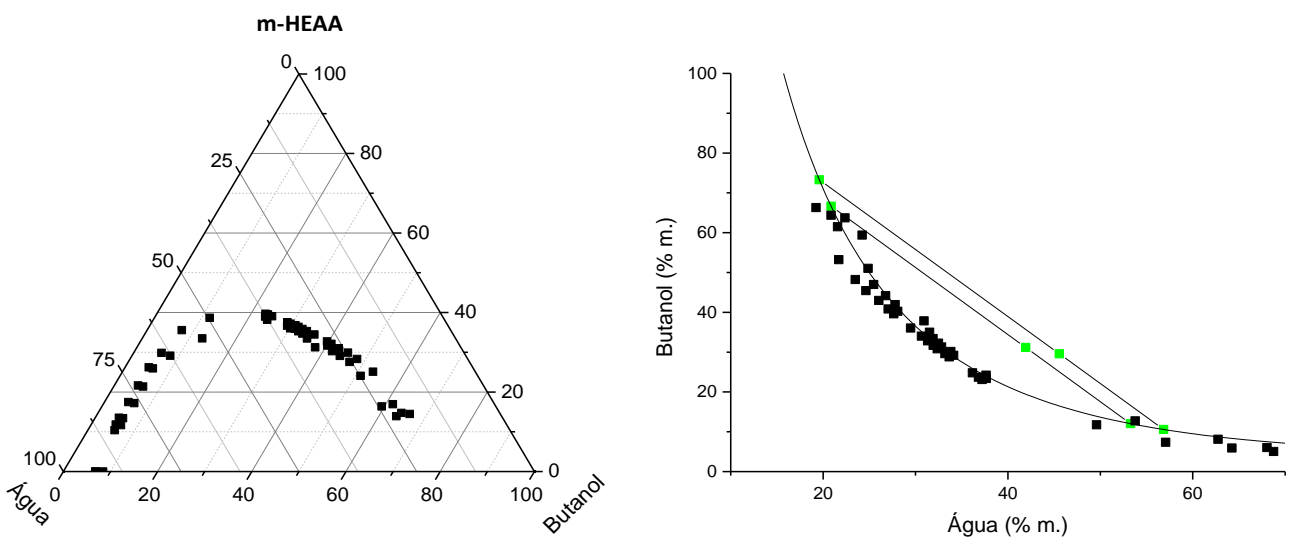

Figura 6 - Dados de equilíbrio do sistema água-butanol-m-HEAA, a $40{ }^{\circ} \mathrm{C}$. 
Os parâmetros que foram obtidos para essa temperatura $\left(40^{\circ} \mathrm{C}\right)$ são mostrados na Tabela 3 .

Tabela 3 - Parâmetros de regressão com a Equação 1, à temperatura de $40{ }^{\circ} \mathrm{C}$.

\begin{tabular}{cccc}
\hline Parâmetro & Coeficiente & Desvio Padrão & $\mathrm{P}$ \\
\hline $\mathrm{a}$ & 1487,078 & 361,515 & 0,0001 \\
$\mathrm{~b}$ & $-0,682$ & 0,05 & $<0,0001$ \\
$\mathrm{c}$ & $-1,07 \mathrm{E}-06$ & $6,53 \mathrm{E}-07$ & 0,1081 \\
\hline
\end{tabular}

$\mathrm{Na}$ Tabela 4 são apresentados os dados de composições das linhas de amarrações exibidas nos gráficos anteriores.

Tabela 4 - Linhas de amarração dos três sistemas em diferentes temperaturas.

\begin{tabular}{ccccccc}
\hline \multicolumn{2}{c}{ Topo } & \multicolumn{2}{c}{ Mistura } & \multicolumn{2}{c}{ Fundo } & \\
\hline Água & Butanol & Água & Butanol & Água & Butanol & $\begin{array}{c}\text { Temperatura } \\
{ }^{\circ} \mathrm{C}\end{array}$ \\
\hline 14,4 & 75,6 & 44,8 & 28,4 & 61,2 & 3,0 & 20 \\
25,6 & 37,76 & 40,06 & 18,03 & 45,12 & 11,12 & 20 \\
58,0 & 12,0 & 44,2 & 28,7 & 37,8 & 36,4 & 30 \\
68,6 & 6,0 & 45,3 & 39,4 & 26,6 & 66,2 & 30 \\
65,1 & 7,7 & 44,9 & 36,3 & 28,5 & 59,5 & 30 \\
19,6 & 73,3 & 45,6 & 29,6 & 56,9 & 10,6 & 40 \\
20,9 & 66,7 & 41,9 & 31,2 & 53,3 & 12,0 & 40 \\
\hline
\end{tabular}

Como pôde ser observado o modelo estudado se ajustou de forma satisfatória à maioria dos pontos, no entanto, na região de mais baixa concentração do soluto o modelo apresentou consideráveis desvios. O aumento da temperatura do sistema promoveu a redução da imiscibilidade dos três componentes, no entanto, esse comportamento não foi observado em todos os casos, pois com a elevação da temperatura de 30 a $40{ }^{\circ} \mathrm{C}$, aparentemente, ocorreu um aumento da imiscibilidade. Outros estudos deverão ser realizados em temperaturas mais elevadas, para verificação do limite da região de miscibilidade desse sistema.

\section{CONCLUSÕES}

Primeiramente, pôde-se concluir que utilizando a metodologia empregada, foi possível obter a região de imiscibilidade da mistura e determinar as linhas de amarração, para as três temperaturas estudadas. Verificou-se que em todas as condições avaliadas, o LI apresentou uma elevada miscibilidade em ambos solventes, apresentando uma leve seletividade para o butanol. Também pôde-se verificar que a Equação 1 representou bem a maior parte da informação experimental obtida, no entanto, não representou bem o sistema para os pontos mais extremos. Com a elevação da temperatura, houve a redução da região de imiscibilidade, no entanto, esse comportamento não foi observado em todos os casos. Assim, concluímos que a membrana 
polimérica, para utilização do líquido iônico m-HEAA, deverá possuir um grau de interação forte o suficiente que impossibilite que o mesmo seja arrastado pelos solventes presentes na célula.

\section{AGRADECIMENTOS}

Ao Professor Álvaro Lima (UNIT-Se), à Fapesb e ao CNPq.

\section{REFERÊNCIAS}

ABASTECENDO COM HIDROGÊNIO: O desafio de armazenar hidrogênio em veículos com célula a combustível numa quantidade que permita viagens longas. Disponível em:

<http://www2.uol.com.br/sciam/reportagens/abastecendo_com_hidrogenio.html>. Acesso em: 5 maio. 2014.

ASENJO, J. A.; MISTRY, S L; ANDREWS, B A; MERCHUK, J C. Phase separation rates of aqueous two-phase systems: correlation with system properties. Biotechnol. Bioeng., v. 79, n. 2, p. 217-23, 20 jul. 2002.

CALMON, F. Era do combustível fóssil termina no século 21. Mas o que vem depois?

Disponível em: <http://carros.uol.com.br/noticias/redacao/2014/03/25/era-do-combustivel-fossiltermina-no-seculo-21-mas-o-que-vem-depois.htm>. Acesso em: 5 maio. 2014.

ENERGÉTICA, EMPRESA. de PESQUISA. Bal. Energ. Nac. 2013: Ano base 2012. p. 288, 2013.

FUEL CELL TODAY. The Fuel Cell Industry Review 2012. Disponível em:

<http://www.fuelcelltoday.com/analysis/industry-review/2012/the-industry-review-2012>. Acesso em: 16 dez. 2012.

PASSOS, H.; FERREIRA, A. R.; CLÁUDIO, A. F. M.; COUTINHO, J.A.P.; FREIRE, MARA G. Characterization of aqueous biphasic systems composed of ionic liquids and a citrate-based biodegradable salt. Biochem. Eng. J., v. 67, p. 68-76, ago. 2012.

RUSSEL, J. B. Química Geral. São Paulo: Makron Books, v.2, 1994. p. 264-326

SCHUTZ, F.; MASSUQUETTI, A.; ALVES, T. W. Demanda e oferta energética: uma perspectiva mundial e nacional para o etanol. Rev. Elet. em Gest., Educ. e Tec. Amb., v. 16, n. 16, p. $3167-3186,2013$.

VILLULLAS, H. M.; TICIANELLI, E. A.; GONZÁLEZ, E. R. Células a combustível: energia limpa a partir de fontes renováveis. QNEsc, n. 15, p. 28-34, 2002. 